\section{FERC Order 841 levels the playing field for energy storage - ADDENDUM}

doi: https://doi.org/10.1557/mre.2019.5

The following footnote should be included in this article [1]:

This paper was commissioned and accepted for publication by Elizabeth Kocs, who served as Editor-in-Chief of this journal from 2015-2018.
Rao Konidena

REFERENCE:

1. Konidena R. (2019). FERC Order 841 levels the playing field for energy storage. MRS Energy \& Sustainability, 6, E5. Cambridge University Press. 